\title{
Analysis of left ventricular regional wall motion in normal neonates
}

\author{
Ayumi Miyazaki, Fukiko Ichida, Ikuo Hashimoto, Shinichi Tsubata, Toshio Okada
}

\begin{abstract}
Objective-To investigate neonatal circulatory change by quantitative analysis of left ventricular regional wall motion.

Design-Random prospective study.

Setting-Department of paediatrics in a teaching hospital.

Participants -66 neonates born after a normal pregnancy, labour, and delivery.

Interventions-Quantitative analysis of left ventricular regional wall motion was performed on cross sectional echocardiograms. $M$ mode, cross sectional, and Doppler echocardiograms were obtained simultaneously.
\end{abstract}

Main outcome measures-Manually traced endocardial contours at end diastole and at end systole were realigned by superimposing the centre of the ventricular mass and the axis. The contours were divided into 24 segments with 24 radii of equal arc from the centre. Then the ratio of the change in area between the outline of the contour and the two hemiaxes was calculated automatically.

Results-There was hyperkinesis of the interventricular septum in the first 24 hours after birth which continued until the end of the first week. Simultaneous echocardiographic examination showed evidence of pulmonary hypertension, as indicated by an increase in the ratio of the right pre-ejection period to the right ventricular ejection time (RPEP/RVET) and of the diameter ratio of the pulmonary artery to the aorta and a shortening of the acceleration time of pulmonary arterial blood flow. These features disappeared within a week.

Conclusions-Hyperkinesis of the interventricular septum may reflect circulatory changes that are characteristic of the early neonatal period.

Department of Paediatrics, Toyama Medical and Pharmaceutical University, Toyama, Japan

Ayumi Miyazaki

Fukiko Ichida

Ikuo Hashimoto

Shinichi Tsubata

Toshio Okada

Correspondence to: Dr Fukiko Ichida,

Department of Paediatrics, Toyama Medical and Pharmaceutical University, Sugitani 2630, Toyama, Toyama 930-01, Japan.

Accepted for publication 22 June 1992
(Br Heart J 1992;68:574-9)

Immediately after birth the lungs take over gas exchange from the placenta and there are major circulatory changes. Pulmonary blood flow increases rapidly and the ductus arteriosus and the foramen ovale close functionally. The pulmonary and the systemic circulations operate in series rather than in parallel. Then the left and right ventricular outputs increase considerably and become equal. Both left ventricular preload and afterload increase because placental blood flow stops and the resistance of the systemic vascular bed is high. Pulmonary arterial blood pressure and vascular resistance fall progressively to the adult level within two to six weeks after birth. These changes were studied in lambs, ${ }^{1-3}$ at neonatal catheterisation $^{45}$ and during echocardiographic examination. . $^{-13}$

We noticed that cross sectional echocardiography showed transient hyperkinesis of the interventricular septum in the early neonatal period. This observation prompted a quantitative analysis of left ventricular regional wall motion and a comparison with $M$ mode, cross sectional and Doppler echocardiographic findings.

\section{Patients and methods}

We performed $M$ mode, cross sectional, and Doppler echocardiographic examinations on 66 neonates and infants. Each of them had had a normal gestation, labour, and delivery. Informed consent was obtained from their mothers according to a protocol approved by the Human Subjects Committee. They were divided into three groups according to their age. Group A was 22 neonates studied within 24 hours after birth; group B, 18 aged 4-7 days; and group C, 26 infants who were about a month old (table 1).

\section{ECHOCARDIOGRAMS}

The echocardiograms were obtained with a Toshiba SSH $60 \mathrm{~A}$ with a $5.0 \mathrm{MHz}$ transducer while the neonates were sleeping. The left ventricular images of the parasternal short axis view at the level of papillary muscles, the apical long axis view, and the apical four chamber view were recorded on the video tapes. The pulsed Doppler scanning frequency was 3.75 MHz. $M$ mode and Doppler tracings were printed on hard copy.

\section{ANALYSIS OF LEFT VENTRICULAR REGIONAL} WALL MOTION

Regional wall motion was analysed with a Kontron Cardio 200 system. The endocardial borders at end diastole and at end systole were traced manually, with a light pen, and were realigned for translation and rotation by superimposing the centre of each contour and the axis according to the floating method. Then the contours were divided into 24 segments by 24 radii of equal arc from the centre and the ratio of change of each area between the outline of the endocardial margin and the two hemiaxes was calculated automatically according to the area method. The end diastolic and the end systolic frames were defined visually as the largest and the smallest left ventricular cavity 
Table 1 Data on noenates (mean (SD))

\begin{tabular}{lccc}
\hline & Group A & Group B & Group C \\
\hline $\mathrm{n}$ & 22 & 18 & 26 \\
Gestational age (week) & $40 \cdot 24(1 \cdot 53)$ & $40 \cdot 22(1 \cdot 53)$ & $40 \cdot 14(1 \cdot 38)$ \\
Body weight at birth (g) & $3404(390)$ & $3304(297)$ & $3261(389)$ \\
Age at study & $10 \cdot 14(6 \cdot 10)$ & $5 \cdot 89(0 \cdot 83)$ & $30 \cdot 92(2 \cdot 13)$ days \\
Body weight at study (g) & $3404(390)$ & $3223(283)$ & $4424(515)$ \\
Heart rate (beats/min) & $120 \cdot 9(16 \cdot 2)$ & $125 \cdot 1(16 \cdot 6)$ & $140 \cdot 5(16 \cdot 0)$ \\
\hline
\end{tabular}

areas, respectively. They coincided with the peak of the $R$ wave and the end of the $T$ wave on the electrocardiogram. The tracing was performed by one observer.

In the short axis view the endocardial borders were traced counter-clockwise from the posterior junction of the right ventricular free wall and the interventricular septum. The centre and the axis were defined as the centre of the mass and the radius drawn from the centre to the start of the tracing. Twenty four small segments were subdivided into six large segments anatomically and the mean ratio of area change was calculated for each large segment (fig 1A).

In the long axis view the contours were traced clockwise from the aortomitral junction. The centre was taken as the mid-point of the left ventricular long axis drawn from the aortomitral junction to the apex. This line was also defined as the axis. As these segments were excluded from the analysis the initial three segments included the mitral orifice. Another 21 segments were analysed and grouped into seven large segments (fig 1B).

In the four chamber view the endocardial contours were traced from the septal side of the mitral orifice. The long axis was drawn from the mid-point of mitral orifice to the apex and the mid-point of it was determined as the axis and the centre. The contours were grouped into six large segments (fig $1 \mathrm{C}$ ).

M MODE, CROSS SECTIONAL, AND DOPPLER ECHOCARDIOGRAPHY

Simultaneous $M$ mode, cross sectional, and Doppler echocardiographic examinations were performed. Right and left ventricular systolic time intervals, the pre-ejection period (PEP), and ejection time (ET) were measured on the hard copies of $M$ mode echocardiograms, and the $\mathrm{PEP} / \mathrm{ET}$ ratio was calculated.

The diameters of the pulmonary artery and the aorta were measured on the parasternal short and long axis views of the cross sectional echocardiograms, and their ratio was calculated. On the short axis view, left ventricular diameter ratio (that is, the ratio of the anteriorposterior wall diameter to the septal-lateral wall diameter) was calculated at the end diastole and at the end systole to assess left ventricular distortion.

Maximal flow velocities and acceleration times (duration from the onset of ejection to the point at peak flow velocity) were measured by pulsed Doppler echocardiography from Doppler velocity curves sampled above the pulmonary valve on the parasternal short axis view and above the aortic valve on the apical long axis view. The existence and the direction of shunt flows through the ductus arteriosus and the foramen ovale were evaluated with a sampling volume in the main pulmonary artery on the parasternal short axis view and at the left side of the patent foramen ovale on the subxiphoid four chamber view.

\section{STATISTICAL ANALYSIS}

Group data were compared by an analysis of variance. A p value less than 0.05 was regarded as statistically significant. All data were expressed as mean (SD).

\section{Results}

REGIONAL WALL MOTION OF THE LEFT VENTRICLE For the first 24 hours after birth the left ventricle was distorted at end systole because the interventricular septum was flattened though the left ventricle was almost circular at end diastole. The interventricular septum was hyperkinetic at this time. One month after birth, however, left ventricular wall motion was like that in adults (fig 2). Hyperkinesis of the interventricular septum showed itself as an increase in the ratio of area change in the septal region in all three views.

In the short axis view the ratio of area change at the mid-septal segment in groups A and B
A

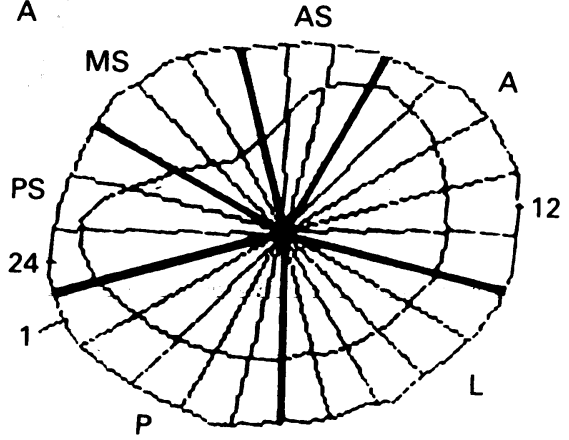

B

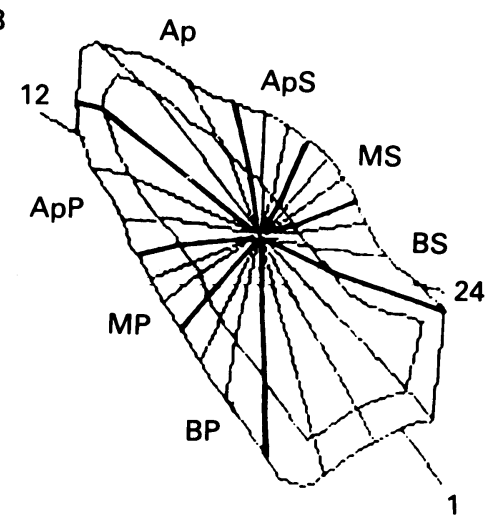

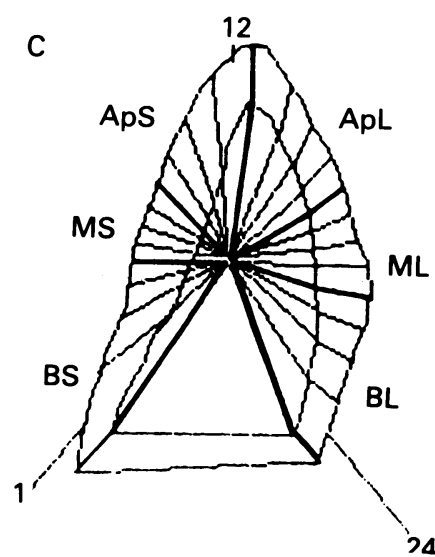

Figure 1 Segmentation scheme in the parasternal short axis view ( $A)$, in the apical long axis view ( $B)$, and in the apical four chamber view ( $C$ ). $P$, posterior; $L$, lateral; $A$, anterior; $A S$, anteroseptal; $M S$, midseptal; $P S$, posteroseptal; BP, basal posterior; $M P$, midposterior; $A p P$, apical

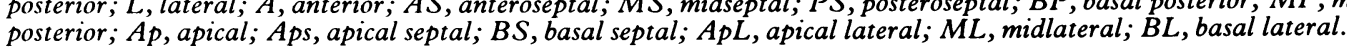


Figure 2 Neonatal left ventricular wall motion in the short axis view 14 hours after birth $(A)$ and a month after birth $(B)$. $d$, end diastole; s, end systole.
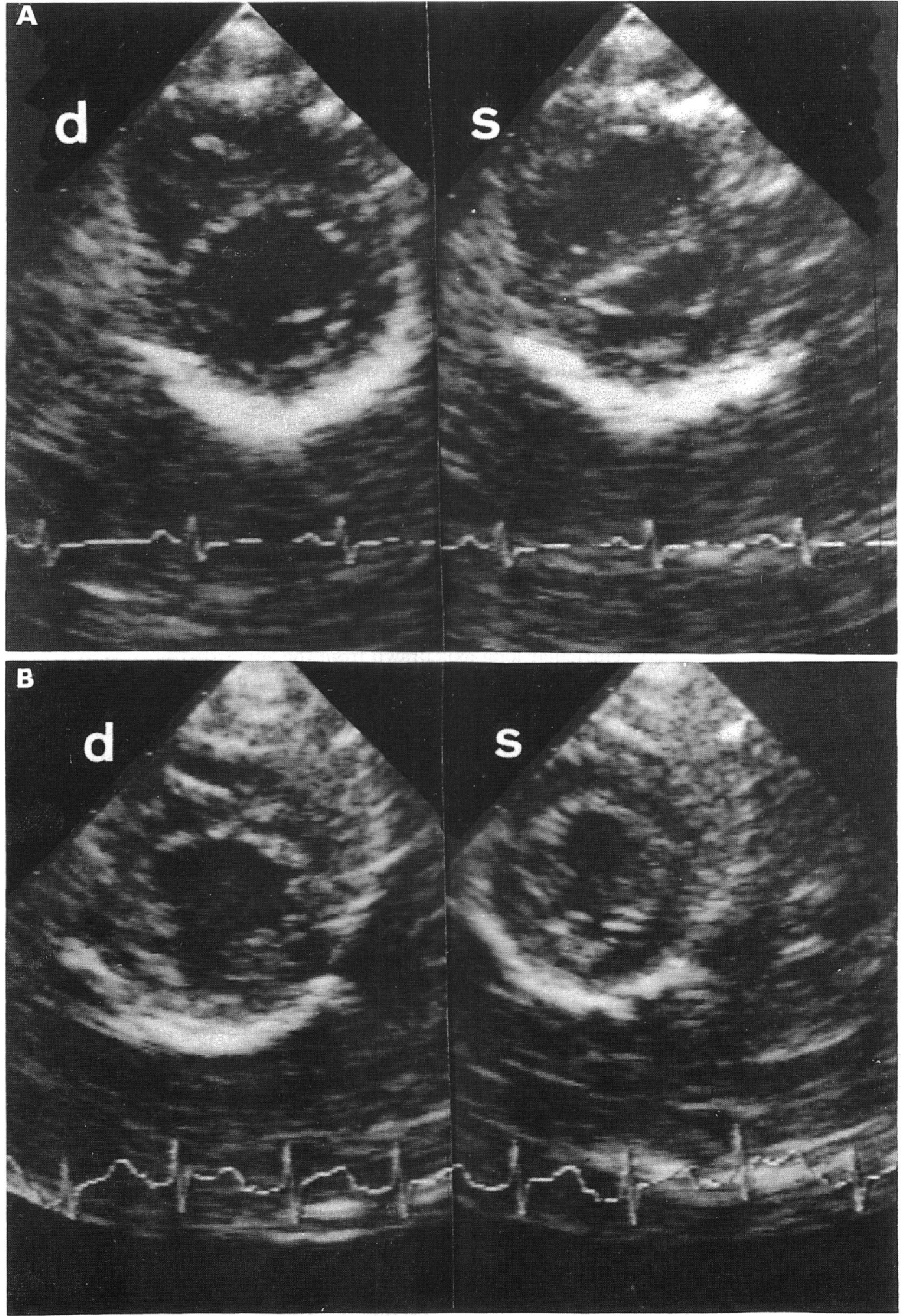

$(66 \cdot 4(8.4) \%$ and $54.6(7 \cdot 6) \%)$ was significantly greater than in group $\mathrm{C}(46 \cdot 8(6 \cdot 3) \%)$. In group $\mathrm{C}$ the ratios for area change were almost equal over all segments, reflecting the circular configurations at end diastole and at end systole (fig 3A).

In the long axis view septal wall motion tended to increase in all groups. But there was no significant change with the age of the group (fig 3B).

In the four chamber view, ratios of area change of all septal segments were significantly higher in groups $A$ and $B$ than in group $C$. The ratios in groups $\mathrm{A}, \mathrm{B}$, and $\mathrm{C}$ were respectively $72 \cdot 1(12 \cdot 7) \%, 55 \cdot 4(21 \cdot 3) \%$, and $42 \cdot 1(11 \cdot 7) \%$ in the basal septal segment; $78.9(10.3) \%, 59.7$ $(15 \cdot 7) \%$, and $43.4(15.4) \%$ in the mid-septal segment; and $70 \cdot 1(10 \cdot 7) \%, 51 \cdot 3(15 \cdot 5) \%$, and $40 \cdot 1(11.4) \%$ in the apical septal segment (fig $3 \mathrm{C})$. In group $\mathrm{C}$ the ratios for area change were similar in all regions.

CROSS SECTIONAL, M MODE, AND DOPPLER ECHOCARDIOGRAPHY (TABLE 2)

Simultaneous cross sectional echocardiographic examinations showed an increase of the 
Figure 3 Changes of left ventricular regional wall motion in the parasternal short axis view $(A)$, in the apical long axis view (B) and in the apical four chamber view (C). There was significant decrease in ratio of area change at the mid-septal (MS) region in the short axis view, and at the basal septal (BS), the mid-septal (MS), and the apical septal ( $A p S$ ) region in the four chamber view $(p<0.05$ by analysis of variance).
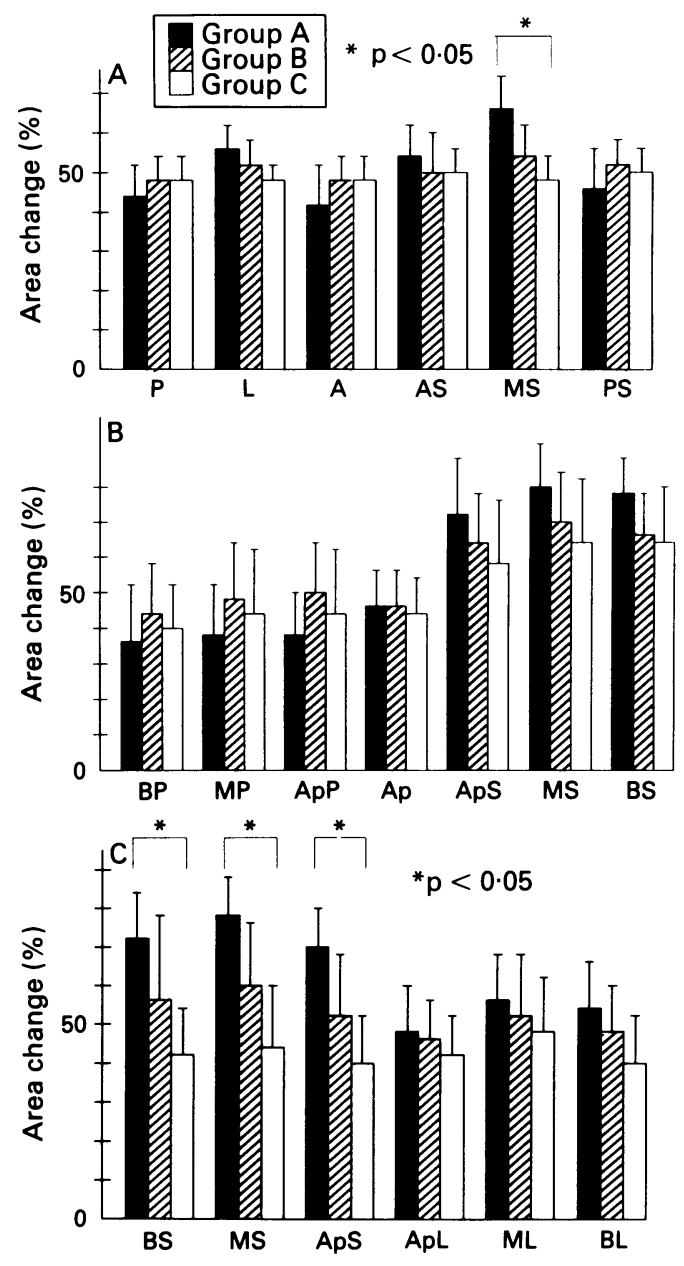

ratio of the diameter of the pulmonary artery to the diameter of the aorta in group A compared with groups $B$ and $C$. The left ventricular diameter ratio at end systole gradually decreased towards one, whereas at end diastole the ratio was already nearly one within 24 hours after birth.

$M$ mode echocardiographic examinations showed that LPEP/LVET in groups $A$ and $B$ was higher than in group C. RPEP/RVET was also higher in group A than in group B or C.

Maximal velocities in the aorta and in the pulmonary artery, determined by pulsed Doppler echocardiographic examinations, increased steadily with the age of the group. The acceleration time in the pulmonary artery was significantly shorter in group A than in group B. Ductal shunt flow was detected as diastolic or continuous forward flow, suggest- ing a bi-directional or a left-to-right shunt, in the main pulmonary artery in $12(57 \%)$ of 21 neonates in group A. It was not detected in groups B or C. Left-to-right shunt flow from early systole to late diastole was seen at the foramen ovale in group A (81\%) accompanied by fluttering of the atrial septum. It was also common in groups B and C, but sometimes it was detected only during inspiration.

\section{Discussion}

The major circulatory changes after birth have been studied by various methods. ${ }^{1-13}$ Because we noticed that cross sectional echocardiography showed hyperkinesis of the interventricular septum in neonates we attempted to measure changes in left ventricular regional wall motion and compare them with other circulatory indices in the first day, week, and month of life.

\section{ANALYSIS OF LEFT VENTRICULAR REGIONAL} WALL MOTION

Cross sectional echocardiographic techniques for regional wall motion analysis have been used to evaluate abnormalities of left ventricular contraction in adults with coronary artery disease $\mathrm{e}^{14-16}$ and to a more limited extent in children. ${ }^{18-20}$ We thought that because of the clarity of the endocardial borders on the screen the method might be more useful in neonates than in adults. But because the heart beat and respiration produce considerable motion of the thorax in neonates we used the floating method rather than the fixed method that is used in adults.

In the short axis view we used the centre of the ventricular mass as the point of superimposition for endocardial contours. In the long axis view and the four chamber view we used the mid-point of the left ventricular long axis as the centre. ${ }^{17}$ Analysis of regional wall motion by these methods showed that during the first week of life the interventricular septum was hyperkinetic. These findings accorded with the visual assessment of the cross sectional echocardiogram. They may have resulted from flattening of the interventricular septum at end systole and from bulging of the interventricular septum toward the right ventricle at end diastole. The hyperkinesis had disappeared by the end of the first month in the short axis and four chamber views. But it was still visible in the long axis view. More consistent results might have been obtained if the left ventricular long

Table 2 Echocardiographic data (mean (SD))

\begin{tabular}{|c|c|c|c|c|c|c|c|c|c|c|c|c|c|}
\hline & \multirow[b]{2}{*}{$\begin{array}{l}A O D \\
(\mathrm{~mm})\end{array}$} & \multirow[b]{2}{*}{$\begin{array}{l}P A D \\
(\mathbf{m m})\end{array}$} & \multirow[b]{2}{*}{$\begin{array}{l}P A D / \\
A O D\end{array}$} & \multicolumn{2}{|l|}{$A P / S L$} & \multirow[b]{2}{*}{$\begin{array}{l}\text { LPEP/ } \\
\text { LVET }\end{array}$} & \multirow[b]{2}{*}{$\begin{array}{l}\text { RPEP/ } \\
R V E T\end{array}$} & \multirow[b]{2}{*}{$\begin{array}{l}A O-F V \\
(\mathrm{~cm} / \mathrm{s})\end{array}$} & \multirow[b]{2}{*}{$\begin{array}{l}A O-A c T \\
(m s)\end{array}$} & \multirow[b]{2}{*}{$\begin{array}{l}P A-F V \\
(\mathrm{~cm} / \mathrm{s})\end{array}$} & \multirow[b]{2}{*}{$\begin{array}{l}P A-A c T \\
(m s)\end{array}$} & \multirow[b]{2}{*}{$\begin{array}{l}P D A \text { flow } \\
(\%)\end{array}$} & \multirow[b]{2}{*}{$\begin{array}{l}\text { PFO flow } \\
\text { (1/(1) }\end{array}$} \\
\hline & & & & End systole & End diastole & & & & & & & & \\
\hline Group A & $\begin{array}{c}7 \cdot 75 \\
(0 \cdot 85)\end{array}$ & $\begin{array}{c}10.09 \\
(0.94)\end{array}$ & $\begin{array}{c}1.33 \\
(0.21)\end{array}$ & $\begin{array}{c}1 \cdot 57 \\
(0 \cdot 20)\end{array}$ & $\begin{array}{c}1 \cdot 18 \\
(0 \cdot 10)\end{array}$ & $\begin{array}{c}0.321 \\
(0.060)\end{array}$ & $\begin{array}{c}0.373 \\
(0 \cdot 111)\end{array}$ & $\begin{array}{r}99 \cdot 3 \\
(14 \cdot 8)\end{array}$ & $\begin{array}{c}53 \\
(14)\end{array}$ & $\begin{array}{c}80.5 \\
(13.5)\end{array}$ & $\begin{array}{c}64 \\
(15)\end{array}$ & $\begin{array}{l}12 / 21 \\
(57)\end{array}$ & $\begin{array}{l}18 / 21 \\
(81)\end{array}$ \\
\hline Group B & $\begin{array}{c}8 \cdot 18 \\
(0 \cdot 81)\end{array}$ & $\begin{array}{r}8.71 \\
(0.92)\end{array}$ & $\begin{array}{c}1.07 \\
(0 \cdot 14)\end{array}$ & $\begin{array}{c}1 \cdot 24 \\
(0 \cdot 21)\end{array}$ & $\begin{array}{c}1.09 \\
(0 \cdot 15)\end{array}$ & $\begin{array}{c}0.319 \\
(0 \cdot 060)\end{array}$ & $\begin{array}{c}0.205 \\
(0.061)\end{array}$ & $\begin{array}{l}104 \cdot 7 \\
(14 \cdot 5)\end{array}$ & $\begin{array}{c}44 \\
(5)\end{array}$ & $\begin{array}{c}93 \cdot 0 \\
(14 \cdot 1)\end{array}$ & $\begin{array}{c}83 \\
(14)\end{array}$ & $\begin{array}{l}0 / 15 \\
(0)\end{array}$ & $\begin{array}{l}10 / 14 \\
(71)\end{array}$ \\
\hline $\begin{array}{l}\text { Group C } \\
\text { ANOVA }\end{array}$ & $\begin{array}{l}8.18 \\
(0.81) \\
\mathrm{p}<0.01\end{array}$ & $\begin{array}{l}9.90 \\
(1.34) \\
\mathrm{p}<0.01\end{array}$ & $\begin{array}{l}1.13 \\
(0.20) \\
\mathrm{p}<0.01\end{array}$ & $\begin{array}{l}1 \cdot 10 \\
(0 \cdot 13) \\
\mathrm{p}<0.01\end{array}$ & $\begin{array}{l}1 \cdot 08 \\
(0 \cdot 11) \\
\text { NS }\end{array}$ & $\begin{array}{l}0.276 \\
(0.050) \\
p<0.05\end{array}$ & $\begin{array}{c}0.213 \\
(0.053) \\
\mathrm{p}<0.01\end{array}$ & $\begin{array}{l}112.1 \\
(15.9) \\
\mathrm{p}<0.05\end{array}$ & $\begin{array}{c}58 \\
(26) \\
\text { NS }\end{array}$ & $\begin{array}{l}93.7 \\
(13.6) \\
\mathrm{p}<0.01\end{array}$ & $\begin{array}{l}72 \\
(16) \\
\mathrm{p}<0.01\end{array}$ & $\begin{array}{l}0 / 18 \\
(0)\end{array}$ & $\begin{array}{l}15 / 18 \\
(83)^{2}\end{array}$ \\
\hline
\end{tabular}

AOD, aortic diameter; PAD, pulmonary artery diameter; AP/SL, left ventricular diameter ratio (anterior-posterior wall diameter to septal-lateral wall diameter); LPEP, left pre-ejection period; LVET, left ventricular ejection time; RPEP, right pre-ejection period; RVET, right ventricular ejection time; FV, flow velocity; Ac'T, acceleration time; PDA flow, left to right or bilateral shunt flow through the patent ductus arteriosus; PFO flow, left to right shunt flow through the patent foramen ovalc; ANOVA, analysis of variance. 
axis had been taken from the apex to the midpoint of the aortic valve.

The position and the shape of the interventricular septum depend on the pressure gradient between left and right ventricles. The radius of curvature of the interventricular septum increased with right ventricular pressure overload, which is most pronounced at end systole. ${ }^{21} 22$ However, the morphological change of the septum may be more sensitive to the change in transseptal pressure gradient in diastole than in systole. ${ }^{23}$

In 1983 Azancot et al used Fourier analysis to sudy the changes in left ventricular shape in the fetal and neonatal period, ${ }^{24}$ and in 1987, Rein et al reported computer analysis of left ventricular regional wall motion by cross sectional echocardiography in normal neonates. ${ }^{20}$ Rein et al's methods and results in the short axis view were similar to ours when we used the centre of the ventricular mass as the index site for superimposition. Because Rein et al also used the centre in the two chamber view the hyperkinesis was not visible. The method we used in the long axis view may be better than theirs for regional wall motion analysis. In our study septal hyperkinesia was more obvious in the four chamber view. We also compared the changes in regional wall motion with the results of $\mathrm{M}$ mode, and Doppler echocardiographic examinations.

CROSS SECTIONAL, M MODE, AND DOPPLER ECHOCARDIOGRAPHIC FINDINGS

The increase in the ratio of pulmonary artery diameter to aortic diameter RPEP/RVET, and the shortening of the acceleration time of pulmonary blood flow were consistent with pulmonary hypertension. ${ }^{2526}$ These features resolved after 24 hours of life, unless pulmonary hypertension continued. On the other hand, the diameter ratio of the anterior-posterior wall to the septal-lateral wall of the left ventricle in the short axis view at the end systole was increased just after birth, reflecting an increase in right ventricular systolic pressure. This ratio gradually decreased during the first month. In contrast, the ratio at end diastole was about one immediately after birth. This finding indicates that diastolic pressure was higher in the left ventricle than in the right ventricle. This accords with the finding that just after birth shunt flow through the foramen ovale was generally left-to-right even in diastole. The Doppler flow pattern of transmitral flow is known to change after birth because of the postnatal increase in transmitral flow and decrease in left ventricular compliance. ${ }^{11}$

Both of the ventricular changes that we found after birth may be the consequences of right ventricular hypertrophy, an increase in right ventricular systolic pressure caused by any remaining pulmonary hypertension, immature left ventricular systolic function, and a rapid increase in left ventricular diastolic pressure caused by the increase of preload and afterload.
IMPORTANCE AND APPLICATION OF REGIONAL WALL MOTION ANALYSIS

Though some indices of pulmonary hypertension had already resolved within a week of life, hyperkinesis of the interventricular septum was still present a week after birth. These findings indicate that changes in ventricular pressure and function continue in the week after birth.

The septal hyperkinesis disappeared in the first month of life-after this it should be regarded as abnormal. Analysis of regional wall motion may be useful in patients with congenital heart diseases because the presence of septal hyperkinesis may indicate pulmonary hypertension or an increase in right ventricular pressure caused by obstruction of the right ventricular outflow tract. Such analysis may also be helpful in evaluating these patients before and after operation.

We think that analysis of regional wall motion is a useful method of identifying abnormal ventricular function in those neonates in whom cardiac or respiratory disease is suspected.

We thank Professor Mary Allen Engle for her advice and assistance in reviewing our typescript.

1 Rudolph AM. The changes in the circulation after birth Their importance in congenital heart disease. Circulation 1970;41:343-59.

2 Rudolph AM. Congenital disease of the heart. Chicago, Year-book Medical Publishers, 1974:17-48.

3 Heymann MA. Fetal and neonatal circulations. In: Moss AJ, Adams F, eds. Heart disease in infants, children and

4 Moss AJ, Emmanouilides G, Duffie ER. Closure of the ductus arteriosus in the newborn infant. Pediatrics 1963;32:25-30.

5 Emmanouilides GC, Moss AJ, Duffie ER, Adams FH. pulmonary arterial pressure changes in human newborn infants from birth to 3 days of age. $J$ Pediatr 1964;65: 327-33.

6 Riggs T, Hirshfeld S, Bormuth C, Fanaroff A, Liebman J Neonatal circulatory changes: an echocardiographic study. Pediatrics 1977;59:338-44.

7 Halon DA, Amitai N, Gotsman MS, Lewis BS. Seria echocardiography during the first $3 \mathrm{mth}$ of life in norma neonates. Eur J Cardiol 1979;9:393-404

8 Ichida F, Aubert A, Denef B, Dumoulin M, Hauwaert LG Cross sectional echocardiographic assessment of great artery diameters in infants and children. $\mathrm{Br}$ Heart 1987;58:627-34

9 Ichida F, Denef B, Dumoulin M, Hauwaert LG. Cardiac chamber growth pattern determined by two-dimensional echocardiography. Heart Vessels 1988;4:26-33.

10 Takenaka K, Waffarn F, Dabestani A, Gardin JM, Henry WL. A pulsed Doppler echocardiographic study of the postnatal changes in pulmonary artery and ascending postnatal changes in pulmonary artery and ascending 1987;113:759-66.

11 Wilson N, Reed K, Allen HD, Marx GR, Goldberg SJ. Doppler echocardiographic observations of pulmonary and transvalvular velocity changes after birth and during the early neonatal period. Am Heart J 1987;113:750-8.

12 Drayton MR, Skidmore R. Ductus arteriosus blood flow during first 48 hours of life. Arch Dis Child 1987;62: $1030-4$

13 Hirsimaki H, Kero P, Wanne O, Erkkola R, Makoi Z Doppler-derived cardiac output in healthy newborn infants in relation to physiological patency of the ductu arteriosus. Pediatr Cardiol 1988;9:79-83.

14 Moynihan PF, Parisi AF, Feldman CL. Quantitative detection of regional left ventricular contraction abnormalities by two-dimensional echocardiography. I. Analysis of methods. Circulation 1981;63:752-60.

15 Parisi AF, Moynihan PF, Folland ED, Feldman CL Quantitative detection of regional left ventricular contraction abnormalities by two-dimensional echocardiography. II. Accuracy in coronary artery disease. Circulation 1981;63:761-7.

16 Schnittger I, Fitzgerald PJ, Gordon EP, Alderman EL, Popp RL. Computerized quantitative analysis of left ventricular wall motion by two-dimensional diography. Circulation 1984;70:242-54.

17 Force T, Bloomfield P, O'Boyle JE, Khuri SF, Josa M, Parisi AF. Quantitative two-dimensional echocardiographic analysis of regional wall motion in patients with 
perioperative myocardial infarction. Circulation 1984;70:233-41.

18 Rein AJJT, Colan SD, Parness IA, Sanders SP. Regional and global left ventricular function in infants with anomalous origin of the left coronary artery from the pulmonary trunk: preoperative and postoperative assesspulmonary trunk: preoperative and postoperative assess-
ment. circulation 1987;75:115-23.

19 Vinent. tricular septal motion and left ventricular function in patients with atrial septal defect. Pediatr Cardio

20 Rein AJJT, Sanders SP, Colan SD, Parness IA, Epstein M. Left ventricular mechanics in the normal newborn. Circulation 1987;76:1029-36.

21 King ME, Braun $\mathrm{H}$, Goldblatt $\mathrm{A}$, Liberthson $\mathrm{R}$, Weyman $\mathrm{AE}$. Interventricular septal configuation as a predictor of right ventricular systolic hypertension in children: a crosssectional echocardiographic study. Circulation 1983;68:68-75.

22 Agata Y, Hiraishi S, Misawa H, Takanashi S, Yashiro K.
Two-dimensional echocardiographic determinants of interventricular septal configurations in right or left ventricular overload. Am Heart J 1985;110:819-25.

23 Kingma I, Tyberg JV, Smith ER. Effects of diastolic transseptal pressure gradient on ventricular septal positransseptal pressure gradient on ventricular
tion and motion. Circulation 1983;68:1304-14.

24 Azancot A, Caudell TP, Allen HD, Horowitz S, Sahn DJ, Stoll C, Thies C, Valdes-Cruz LM, Goldberg SJ. Analysis of ventricular shape by echocardiography in normal fetuses, newborns, and infants. Circulation 1983;68 1201-11.

25 Hirschfeld S, Meyer R, Schwartz DC, Korfhagen J, Kaplan $S$. The echocardiographic assessment of pulmonary artery pressure and pulmonary vascular resistance. Circulation 1975;52:642-50.

26 Kitabatake A, Inoue M, Asao M, Masuyama T, Tanouchi J, Morita T, Mishima M, Uematsu M, Shimazu T, Hori M, Abe $\mathrm{H}$. Noninvasive evaluation of pulmonary hypertension by a pulsed Doppler technique. Circulation 1983;68:302-9. 